Original Research Paper

\title{
Sosialisasi dan Pendampingan Bumdes Menjadi TDC di Desa Kumbang Kecamatan Masbagik
}

\author{
Wahyunadi $^{*}$, Yanti Rizki Sustriawati ${ }^{1}$, Warmawati ${ }^{1}$, Wiwin Hidayat ${ }^{1}$ \\ ${ }^{1}$ Universitas Mataram, Indonesia;
}

https://doi.org/10.29303/jpmpi.v3i2.909

Sitasi: Wahyunadi., Sustriawati, Y. R., Warmawati., \& Hidayat W. (2021). Sosialisasi dan Pendampingan Bumdes Menjadi TDC di Desa Kumbang Kecamatan Masbagik. Jurnal Pengabdian Magister Pendidikan IPA, 4(3)

\author{
Article history \\ Received: 22 Juli 2021 \\ Revised: 31 Juli 2020 \\ Accepted: 1 September 2021 \\ *Corresponding Author: \\ Wahyunadi, Universitas \\ Mataram, Indonesia; \\ Email: \\ ghalibywahyu@gmail.com
}

\begin{abstract}
Program mahadesa trade and distribusi center (TDC) merupakan program unggulan yang dikembangkan oleh PT.Gerbang NTB Emas yang diharapkan mampu mengangkat produk IKM/UKM lokal agar dapat bersaing dipasar nasional dan global, sehingga memperkuat infrasturktur perekonomian didesa. Kegiatan ini dilaksanakan pada bulan Juni-Agustus 2021 di Desa Kumbang, Kecamatan Masbagik, Kabupaten Lombok Timur. Kegiatan sosialisasi dilakukan menggunakan metode wawancara langsung dan pengisian kuisioner melalui google form. Sehingga didapatkan 30 responden yang terdiri dari empat jenis golongan pekerjaan (Ibu rumah tangga, Petani, Pedagang, dan Pegawai). Hasil yang didapatkan dari terlaksananya program sosialisasi program Mahadesa yaitu data survey menunjukan bahwa sebagian besar warga di Desa Kumbang masih belum memahami secara detail mengenai Mahadesa yang mengakibatkan masyarakat takut untuk mengikuti program Mahadesa. Data survey mempengaruhi hasil dari data sosialiasi program Mahadesa, yang berarti jumlah masyarakat yang belum mengetahui mengenai Program Mahadesa meningkat dari data survey yang diperoleh.
\end{abstract}

Keywords: Mahadesa, BUMDES, TDC, Digitalisasi, Lombok

\section{Pendahuluan}

Saat ini, dunia industri global sedang memasuki era baru yang dikenal sebagai Revolusi Industri 4.0 atau yang juga dikenal sebagai era digital 4.0. Industri 4.0 sendiri ialah fase baru di revolusi industri yang fokus di interkonektivitas, otomatisasi, machine learning, dan real time data.

Program yang dikeluarkan oleh gubernur NTB untuk mengimbangi revolusi industri 4.0 atau era digital tersebut ialah dengan program Mahadesa Trade Distribution Center (TDC) yang ditujukan untuk mempermudah wirausaha desa menuju pemasaran digital.

Program mahadesa trade and distribusi center (TDC) merupakan program unggulan yang dikembangkan oleh PT.Gerbang NTB Emas yang diharapkan mampu mengangkat produk IKM/UKM lokal agar dapat bersaing dipasar nasional dan global, sehingga memperkuat infrasturktur perekonomian didesa.

Desa Kumbang merupakan salah satu desa terbaik yang ada di NTB saat ini. Desa Kumbang sendiri mewakili NTB dalam lomba Desa Benderang Informasi tingkat nasional. Hal tersebut membuktikan bahwa Desa Kumbang merupakan Desa yang sudah maju sehingga Desa Kumbang merupakan sasaran yang tepat untuk mengaplikasikan program MAHADESA.

Pesatnya perkembangan Desa Kumbang tidak menutup kemungkinan adanya masyarakat yang masih belum bisa mengimbangi perubahan yang terjadi. Adanya penerapan mahadesa sendiri, masih banyak kalangan masyarakat yang belum 
mengetahui maksud dan tujuan dari mahadesa. Selain permasalahan diatas juga desa kumbang merupakan salah satu desa yang terdampak pandemi Covid-19. Banyak masyarakat yang mengeluh akan sulitnya perekonomian di masa pandemi ini, khususnya para pelaku UMKM. Pandemi Covid-19 telah membuat mayoritas sektor ekonomi tidak bisa berkembang dan banyak pelaku ekonomi yang berakhir gulung tikar.

Berdasarkan permasalahan tersebut dibutuhkan inovasi-inovasi untuk produk-produk UMKM agar dapat berjalan lancar dan mudah diakses ditengah pandemi. Oleh karena itu, KKN Tematik dengan tema Mahadesa ini bertujuan untuk meningkatkan perekonomian desa dan memberikan pemahaman kepada masyarakat bahwa pentingnya belanja di desa sendiri dan praktis tanpa harus keluar rumah, hanya dengan sistem digitalisasi melalui program TDC (Trade Distribution Center) yang dimana BUMDes berperan sebagai fasilitator yang dapat memenuhi pesanan rumah tangga masyarakat.

\section{Metode}

Metode yang diterapkan dalam program kegiatan ini dilakukan menggunakan metode wawancara langsung dari rumah ke rumah warga. Kemudian pengisian kuisioner melalui google form untuk mengetahui pemahamn masyarakat tentang program Mahadesa.

\section{Hasil dan Pembahasan}

Program kerja utama dalam KKN (Kuliah Kerja Nyata) tematik Desa Kumbangada 3 yaitu :

\section{Sosialisasi Program Mahadesa TDC (Trade DistributionCenter)}

Merupakan hasil kerjasama antara pemerintah Provinsi NTB dengan Mahadesa untuk mengembangkan pembangunan ekonomi daerah baik BUMD Provinsi, Kabupaten, hingga BUMDES, sebagai pelaku langsung yang mengelola berbagai potensi bisnis di NTB. PT. GNE dengan program TDC Mahadesanya saat ini sudah menggeliat dengan pemberdayaan dan peningkatan ekonomi dari desa. Pemerintah saat ini sangat konsen menjadikan desa dengan program Mahadesanya sudah mulai dan terus berupaya menciptakan kolaborasi dalam pembangunan TDC mahadesa disetiap desa yang ada di wilayah NTB.

Secara umum, program TDC (Trade Distribution Center) ini merupakan suatu sistem pemasaran terintegrasi (integrated marketing)berbasis digital (Muhammad, 2020).

Infrastruktur ekonomi digital adalah system digital managemen perdagangan dan distribusi yang membantu mempermudah setiap wirausaha, pelanggan, principle, distributor, keluraga, UMKM, BUMD, BUMDES, dan partisipan yang berkepentingan dalam rantai bisnis di Provinsi NTB untuk mendapatkan layanan yang secara otomatis terhubung satu dengan yang lainnya sesuai kebutuhannya dengan platform system digital. Melalui program Mahadesa, UMKM akan dikembangkan melalui rantai bisnis pemberdayaan desa secara ekonomi dan masyarakat mendapatkan berbagai jenis kebutuhannya tanpa harus keluar rumah.

GNE berkolaborasi dengan BUMDes menggunakan sentuhan teknologi kekinian tersebut untuk menciptakan nilai lebih. BUMDes saat ini sudah resmi mempunyai badan hokum yang kedepannya bisa membuat PT yang sesuai tertuang dalam UU nomor 11 tahun 2020 tentang cipta kerja tepatnya dibagian ke 10 yaitu pasal 117 .

BUMDes dalam hal ini dilibatkan sebagai ujung tombak, sekaligus sebagai fasilitator yang akan merekap dan memenuhi pesanan rumah tangga (masyarakat). Masyarakat berbelanja layaknya ke ritel modern, cukup hanya dari rumah melalui fasilitas Mahadesa ini.

Program ini selain memperkuat infrastruktur perekonomian di desa, juga diharapkan mampu mengangkat berbagai produk IKM/UKM lokal untuk bisa bersaing, tidak hanya menjadi tuan di negerinya sendiri, tetapi juga dipasar nasional dan global.

Sosialisasi program Mahadesa yang dilakukan bertujuan untuk mengedukasi masyarakat atas adaptasi kebiasaan belanja terencana dan memberikan pemahaman tentang program mahadesa itu sendiri.

Sosialisasi program mahadesa tersebut dilakukan dengan caradoor to door dan pengisian Google form. Sebanyak 30 sampel dari 6 dusun yang dipilih berdasarkan jenis pekerjaan (IRT, Pedagang, Petani dan Pegawai) yang mengisi kuisioner dan mengedukasi masyarakat tentang belanja terencana. 
Hasil dari sosialisasi program mahadesa memberikan pemahaman masyarakat terhadap adanya Mahadesa TDC dengan perbandingan 20/30 (dua puluh orang warga memahami adanya Mahadesa TDC dari tiga puluh). Masyarakat yang menerapakan belanja terencana terdiri dari 9 orang Ibu rumah tangga, 10 orang pedagang, 5 Pegawai dan 6 orang petani.

Gambar 4.1 Kegiatan sosialisasi program Mahadesa.Ket: A. Sosialisasi kepada masyarakat; B. Diskusi bersama direktur BUMDES

\section{Digitalisasi Marketing Produk BUMDes}

Pesatnya perkembangan teknologi, dunia digital, dan internet tentu juga berimbas pada dunia pemasaran. Trend pemasaran di dunia beralih dari yang semula konvensional menjadi digital. Digital marketing merupakan aktivitas, institusi, dan proses yang difasilitasi oleh teknologi digital dalam menciptakan, mengomunikasikan dan menyampaikan nilai-nilai kepada konsumen dan pihak yang berkepentingan lainnya (Kannan, 2017). Menurut Chaffey et al., (2013) mendefinisikan digital marketing sebagai penggunaan teknologi untuk membantu aktivitas pemasaran yang bertujuan untuk meningkatkan pengetahuan konsumen dengan cara menyesuaikan dengan kebutuhan mereka. Digital marketing merupakan kombinasi pemasaran antara produsen, perantara pasar dan calon konsumen. Strategi digital marketing ini lebih prospektif karena memungkinkan para calon pelanggan potensial untuk memperoleh segala macam informasi mengenai produk dan bertransaksi melalui internet. Di satu sisi, digital marketing memudahkan pebisnis memantau dan menyediakan segala kebutuhan dan keinginan calon konsumen, di sisi lain calon konsumen juga bisa mencari dan mendapatkan informasi produk hanya dengan cara menjelajah dunia maya sehingga mempermudah proses pencariannya.

Tujuan dari adanya Digitalisasi Marketing ini dilakukan untuk mempermudah pelayanan di BUMDes Amanah Desa Kumbang dan produkproduk lokal desa tersebut dapat dikenal dan bersaing dipasar nasional dan global. Hasil dari program digitalisasi ini adalah pemasaran produk secara digital dan adanya katalog produk BUMDes Amanah Desa Kumbang.

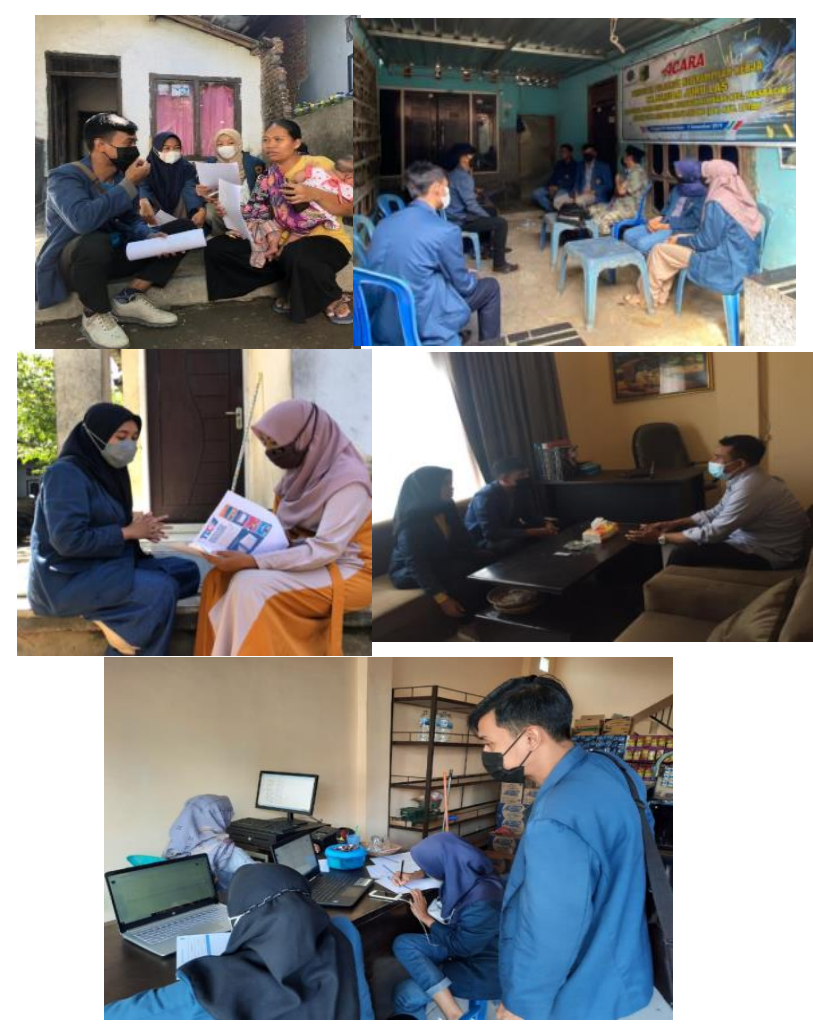

Gambar 4.2 Pendataan produk BUMDES bersama dengan staff TDC.

\section{Pengisian Data Dasawisma TDC}

Pemberdayaan pemuda dan dasawisma menjadi salah satu solusi untuk mengurangi angka pengangguran yang menjadi permasalahan nasional hari ini. TDC Mahadesa merupakan salah satu upaya menciptakan peluang kerja serta pemberdayaan yang berkelanjutan. TDC Mahadesa bukan hanya menyediakan bahan kebutuhan seharihari tapi sudah mulai dengan pelayanan perbankan. Sinergi dan kolaborasi merupakan ruh untuk bersama-sama membangun ekonomi dari desa baik ditingkat pusat, provinsi, kabupaten, swasta dengan satu visi dan misinya yang sama untuk mewujudkan ekonomi NTB yang Gemilang.

Kegiatan pengisian Data Dasawisma ini dilakukan untuk membantu staff BUMDes mempercepat launching aplikasi TDC. Selain itu kegiatan ini bertujuan untuk memberikan pembelajaran baru bagi kelompok KKN kami, sehingga dapat menguasai aplikasi TDC dan membantu staf TDC untuk melengkapi data-data member. 


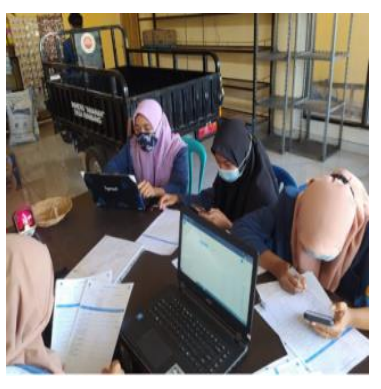

Gambar 4.3 Pengisian form data dasawisma member TDC.

\section{Kesimpulan}

Berdasarkan program yang telah dilaksanakan hasil yang didapatkan dari sosialisasi program Mahadesa yaitu data survey menunjukan bahwa sebagian besar warga di Desa Kumbang masih belum memahami secara detail mengenai Mahadesa yang mengakibatkan masyarakat takut untuk mengikuti program Mahadesa. Data survey mempengaruhi hasil dari data sosialiasi program Mahadesa, yang berarti jumlah masyarakat yang belum mengetahui mengenai Program Mahadesa meningkat dari data survey yang diperoleh.

\section{Daftar Pustaka}

Idah, Y. M., \& Pinilih, M. (2019). Strategi Pengembangan Digitalisasi UMKM

Jupri, A., Prasedya, E. S., Azima, M. F., Praja, F. M. D., Rizaldy, W., Zuhal, Y. A., Laeli, S., Rohmi, H., Hadi, R. L., \& Walida, N. (2021). Proyek di Desa Pendampingan Mahadesa untuk Sosialisasi TDC (Trade \& Distribution Center) Desa Labuhan Haji. Jurnal Pengabdian Magister Pendidikan IPA, 4(1)

Sanjaya, A. K. P., Hartati, S. P. N., Premayani, W. W. N. (2020). Pemberdayaan Pengelola Badan Usaha Milik Desa (BUMDes) Berdikari Melalui Implementasi Digital Marketing Sistem. Jurnal Pengabdian Kepada Masyarakat, 3(1).

Slamet, R., dkk (2016). Strategi Pengembangan UMKM Digital Dalam Menghadapi Era Pasar Bebas. Jurnal Aplikasi Ipteks Untuk Masyarakat ISSN 1410-5675 Vol. 6, No. 2, juni 2017: 78-82. 